Sixma, H.J., Calnan, S., Calnan, M., Groenewegen, P.P.

User involvent in measuring service quality of local authority occupational therapy services: a new approach.

International Journal of Consumer Studies: 25, 2001, nr. 2, p. 150-159

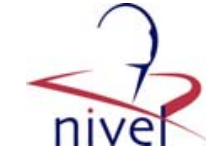

\begin{tabular}{l|l}
\hline Postprint Version & 1.0 \\
\hline $\begin{array}{l}\text { Journal website } \\
\text { Pubmed link }\end{array}$ & http://www.blackwell-synergy.com/toc/ijc/25/2 \\
\hline DOI & $10.1046 / j .1470-6431.2001 .00190 . x$ \\
\hline
\end{tabular}

\title{
User involvement in measuring service quality of local authority occupational therapy services; a new approach
}

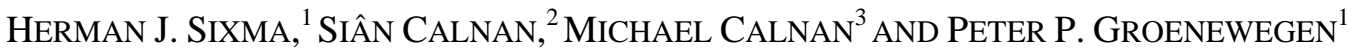

1 Research Department, Nivel - Netherlands Institute for Health Services Research, The Netherlands 2 Bristol City Council, UK

3 MRC HSRC, Department of Social Medicine, University of Bristol, UK

Correspondence H. J Sixma, MSc, PhD, Senior Researcher, Nivel - Netherlands Institute for Health Services Research, The Netherlands. E-mail h.sixma@nivel nl

\begin{abstract}
The aim of this paper is two-fold: (i) to describe the development of a new measuring instrument for quality of care from the perspective of the users of local authority Occupational Therapy (OT) services, and (ii) to evaluate the potential of the new instrument as a standardized approach for involving consumers in the service evaluation of home health care services. A combination of qualitative and quantitative methods was used. Focus group discussions with users of local authority OT-services preceded a postal survey. Questionnaires were sent to a random sample of 997 users of the local authority OT Bureau in Kent, UK. The response rate was 55\%. A valid and reliable instrument the QUOTE-OT Services questionnaire - was developed, which reflects the (expressed) needs of the users of OT services. Feasibility tests showed that information from the instrument can play an important role in follow-up activities that aim at continuous quality improvement. The QUOTE-OT Services instrument can be seen as an example of a new generation of questionnaires for assessing user views in quality of care research. Potentially, instruments such as the QUOTE-OT questionnaire contribute to the empowerment of users in programmes that aim at improving the quality of home health care services.
\end{abstract}

\section{INTRODUCTION}

An understanding of user views about services provided by health and social care organizations is extremely important for the maintenance of good relationships between users and health and social care providers and the adherence to medical and social regimes. ${ }^{1-3}$ Also, user views are vital to quality assurance (QA) and quality improvement (QI) programmes and the expected outcome of care. ${ }^{4-7}$

Within quality of care research there is a longstanding tradition that user views are best measured by satisfaction questionnaires. (In this article we will use the term 'users' as an equivalent for consumers, clients and patients.) However, the relevance of satisfaction studies for QA and QI programmes in the health and social care sector is often questioned because of the lack of a theoretical or conceptual framework, doubts about the reliability and validity of satisfaction scores and the ambiguity of the concept of 'user satisfaction' ${ }^{8-12}$ Also, it has been established that measuring instruments for patient satisfaction are mainly based on the perspective of researchers, with users only being involved in such studies as respondents. ${ }^{13}$ This casts doubts on the validity of such instruments for measuring quality of care through the users' eyes. Finally, most patient satisfaction instruments tend to focus on general aspects of quality of care and not on aspects that are particularly relevant for specific groups of users 
Sixma, H.J., Calnan, S., Calnan, M., Groenewegen, P.P.

User involvent in measuring service quality of local authority occupational therapy

services: a new approach.

International Journal of Consumer Studies: 25, 2001, nr. 2, p. 150-159

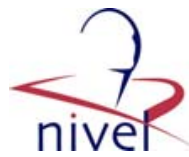

or specific services. Although appropriate in general population studies, such generic aspects deny the specific needs and experiences of large subgroups within the population, such as patients with specific chronic diseases or other frequent users of health and social care services.

Quality of care from the users' perspective can be defined as the totality of features and characteristics of a health care product or health care service that have a bearing on its ability to satisfy the 'needs' of users. ${ }^{14}$ Implicit in this definition are elements of a balanced evaluation between experiences and expectations ${ }^{15}$ and the distinction between cognitive evaluations and affective responses of respondents. ${ }^{11}$ Although, in theory, user satisfaction is related to the 'experiences' and 'needs' of respondents, empirical studies tend to focus on the result: user (dis)satisfaction.

Alternative approaches were developed by Parasuraman et al. ${ }^{16,17}$ and Zastowny et al. ${ }^{18}$

Parasuraman's Service Quality (SERVQUAL) model directly measures expectations and experiences of respondents. Zastowny's Patient Experience Survey (PES) model concentrates on three quality of care elements: performance, importance and impact. Good performance (or problem frequency) is associated with good quality of care, whereas relatively poor performance is associated with poor quality of care. As some problems are more important to users than others, an importance component is added. Problem incidence and importance scores are combined into quality impact indices, which can form the basis for the selection of quality aspects for QI programmes. Both models are in line with the idea that questions asking for 'reports' tend to reflect the quality of care better and are more interpretable and actionable for QI purposes than ratings of (dis)satisfaction or excellence. ${ }^{19}$ The combination of the SERVQUAL and the PES models provides us with a conceptual framework based on four elements: expectations, importance scores, performance scores and quality impact indices. In this framework, 'expectations' refer to the 'needs' or 'desires' of users of health and social care services and should cover different aspects of the delivery of health and social care services, reflecting the multidimensionality of the quality of care concept. ${ }^{8,20-25}$

If frequent users of health and social care services are considered as experts, then users should be involved in research and development processes at as early a stage as possible and then follow the process through. This process usually starts with identifying a research topic and continues with prioritizing these topics, carrying out the research, analysing and interpreting the results of research, disseminating these results and evaluating the research process. Usually, three types of user involvement are recognized: consultation, collaboration and user control. ${ }^{26}$ In principle, there is a role for each of these types of involvement within research projects.

The aim of this paper is two-fold: (i) to describe the development of a new measuring instrument for quality of care from the perspective of the users of local authority Occupational Therapy (OT) services, paying special attention to the way users of OT services were involved in this development process, and (ii) to evaluate the potential of the new instrument as a standardized approach for involving consumers in the service evaluation of home health care services.

\section{METHOD}

As the new instrument for measuring quality of care from the perspective of the users of local authority OT services is building on previous work that was carried out as part of an ongoing research programme in the Netherlands, we will first give a short description of this programme and the instruments that were developed. Next, we will describe in more detail the methods that were used as part of the development process of the new QUOTE-OT Services instrument.

\section{The QUOTE-family of instruments}

The QUOTE-family of instruments (the acronym QUOTE stands for QUality Of care Through users' Eyes) was developed to measure quality of care from the perspective of different user groups. Part of the instruments focus on specific disease categories, such as people with asthma and COPD (chronic obstructive pulmonary diseases), diabetes mellitus and rheumatic diseases. ${ }^{27-29}$ Other instruments aim at specific groups such as frail, elderly people and disabled people, ${ }^{30,31}$ or at specific services such as services that users get from general practitioners or physiotherapists.

QUOTE-instruments are developed as selfadministered questionnaires based on a combination of qualitative and quantitative methods. ${ }^{32}$ User groups participate in this process from the very beginning and all the way through. Each QUOTE instrument contains a generic part, with quality aspects that are 
Sixma, H.J., Calnan, S., Calnan, M., Groenewegen, P.P.

User involvent in measuring service quality of local authority occupational therapy

services: a new approach.

International Journal of Consumer Studies: 25, 2001, nr. 2, p. 150-159

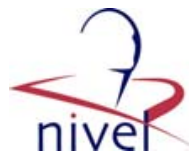

relevant for all users, and a category-specific part, with quality aspects that are particularly relevant for a specific group of users of health services or that can be typified as service-specific. Generic aspects are, for example, the wish 'to be taken seriously' or 'enough time during consultations'. Examples of category-specific items are 'a smoke-free waiting and consultation room' (COPD-patients) and 'comfortable chairs in the waiting room' (rheumatic patients).

Quality aspects included in the QUOTE-instruments reflect the multidimensionality of the quality of care concept. These aspects refer to a process dimension (courtesy, professional competence, information, perceived autonomy) and a structure dimension (continuity of care, accessibility/availability, costs, assessment procedures, etc.). Under specific circumstances (e.g. such as the instrument that was developed in collaboration with people that went through cataract surgery) an outcome dimension is added. The development of the QUOTE-OT Services instrument builds upon earlier work that was carried out as part of the development of the QUOTE-Disabled instrument.

\section{The qualitative phase}

As a first step in the development of the QUOTE-OT services instrument, the questions and prose text of the original Dutch version of the QUOTE-Disabled questionnaire were translated. The original Dutch version, which was based on a combination of qualitative and quantitative methods, was translated by two mother tongue English and fluent Dutch speakers, followed by a panel discussion by bilinguals. Backward translation was performed by two mother tongue Dutch and fluent English speakers and was followed by another panel discussion and a check for linguistic correctness. The result of this translation process - a preliminary English version of the QUOTE-Disabled instrument was used as background information for the researchers at the start of a series of focus group discussions (FGDs).

Two groups consisted of disabled people: one group of 18 people and a second group of 10 people. Participants were recruited through the Kent Social Services Occupational Therapy Service (the Kent OT Bureau). Men and women were almost equally represented; participants varied in age from 35 to 68 years. A large majority of the participants experienced serious limitations in daily life activities; approximately half of the group members were wheelchair users. In both groups, perceived health was rated between 'good' and 'fair'. Almost $40 \%$ of the participants lived on their own, being single, divorced or widowed. Some group members knew each other through working or socializing together. The aims of the first FGD were three-fold: (1) to discuss important quality of care aspects especially relevant for disabled people in the United Kingdom in general, (2) to derive and discuss specific quality aspects that refer to the work of local authority OT services, and (3) to hear the participants' comments on the translated Dutch version of the QUOTE-Disabled questionnaire and the relevance of these aspects for the situation of OT-users in the UK. The aim of the second and third FGD (apart from the session with OT-users, six OT and social service managers and senior practitioners [four females and two males], all having more than 10 years of professional experience in delivering health and social care services to disabled people) was to comment on the results of the first group meeting. Sessions lasted about $2^{1} /^{2}$ hours and were conducted in the presence of two experienced moderators on the basis of a semi-structured discussion guide. Included in this guide were: (1) an introductory text/question to start the discussion, (2) a list with quality of care dimensions and sub-dimensions to structure comments that were made, (3) the list of quality aspects that were included in the preliminary version of the QUOTE-Disabled instrument, and (4) information about the next stages of the project. Parts 1,3 and 4 of the discussion guide were also put on overhead sheets and presented to the OTusers participating in the group discussions. Prior to the meeting, participants received an introductory letter informing them about the objectives of the FGD, the background of the study and the formal arrangements that were made to accommodate the participants.

During the session, group dynamics (which is one of the great advantages of working with focus groups, ${ }^{33,34}$ ) worked well. Participants did not feel any reluctance in telling their own histories and experiences, sharing common experiences, disagreeing with each other and receiving information from more experienced co-participants. Sometimes participants clearly showed their interest in user rights and user autonomy: ('I think that users should have a clear voice in all the services available and should be involved in the decision making process ...'). OT-specific topics that were frequently mentioned during the discussion refer to the information that is offered to users ('I want to have 
Sixma, H.J., Calnan, S., Calnan, M., Groenewegen, P.P.

User involvent in measuring service quality of local authority occupational therapy services: a new approach.

International Journal of Consumer Studies: 25, 2001, nr. 2, p. 150-159

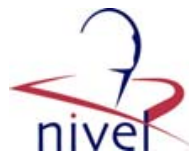

adequate information about all the services available and the procedures to be followed; something like an information booklet.'), assessment procedures ('There are good days, and there are bad days. If I put all my energy in the assessment, because I want to do as good as possible, I know that I can spoil things for myself. I think that assessments should refer to the normal situation, to avoid that the impression they get looks better than it actually is.') and waiting times ('waiting time for adaptations should be as short as possible and I want information on a regular basis about the status of the request.'). Other quality aspects that were mentioned refer to generic topics, such as courtesy ('during an appointment everything needs to be discussed with me and in my presence; not behind my back!' and 'sometimes care givers treat you like a small child'), good communications between the different services ('I really hate the "red tape"; the feeling that you're telling the same story twice and have to do the same test over and over again.') and the way information is given to the users ('All the information I receive, oral as well as in writing, should be in clear and normal language.').

The 53 quality aspects that were derived from the first brainstorming session with OT-users were printed on a deck of cards, with one aspect listed on each card. In line with the concept mapping procedure, ${ }^{35}$ FGD participants were asked (1) to sort these cards into piles in a way 'that makes sense to them', by placing similar aspects or aspects that belonged to the same 'family' into the same pile, and (2) to rate each aspect on a 1-5 scale ( 1 = 'relatively unimportant' and $5=$ 'extremely important').To avoid all aspects ending up in one or two categories, participants were instructed that each of the five scale categories should include about the same number of (approximately 10) quality of care aspects. The results of the sorting and rating jobs were recorded and entered in the concept mapping computer program to plot the different quality aspects in a spatial map and to calculate the relative importance scores of all 53 aspects.

FGDs and concept mapping resulted in a draft version of the QUOTE-OT instrument consisting of 40 quality aspects. The 40 aspects were selected on the basis of the importance scores, their contribution to the different quality of care (sub)dimensions in the instrument- under-development and their face validity for each of the participants of the second and third FGD. Of these 40 quality aspects, 23 items can be typified as 'generic aspects for disabled people; the remaining 17 aspects could be labeled as 'OT-specific'. The 40 quality aspects that were selected for inclusion in the preliminary version of the QUOTE-OT instrument can be seen as the 'expectations' of users with regard to the service quality of the OT bureau in Kent. The 40-aspect version of the QUOTE-OT instrument was used in the quantitative phase of the study.

\section{The quantitative phase}

To evaluate the potential of the new instrument as a standardized approach for involving consumers in the evaluation of home health care services, the feasibility and psychometric characteristics of the 40-aspect version of the QUOTE-OT instrument were explored by including the instrument in a postal questionnaire. Accompanying questions referred to sociodemographic variables (gender, marital status, age, household, employment position, years of education), questions about the health profile of the respondents (SF-12) and the UK version of the QUOTE-Disabled instrument. The questionnaire was sent to a 1 in 12 systematic random sample of 1000 users selected from the computerized records of the Kent Social Services OT Bureau. The inclusion criteria were (1) the presence of serious, physical limitations, registrable as physically disabled, (2) being non-institutionalized, (3) being 16 years of age or older, and (4) having been allocated to a member of the OT Bureau within the last year drawn from the files of the local Social Services OT Service. Questionnaires were distributed in June 1998 and were followed by one reminder.

The original sample was reduced by three because of two duplicate names and addresses and one blank address. The remaining sample of 997 was reduced further by 58 deceased people, 3 Post Office returns with people no longer living at this address and 43 people who were unable to complete the questionnaire because of illness or disability. Of the remaining sample $(N=893), 489$ persons completed the questionnaire (including 6 questionnaires that were only partially completed), 41 persons refused to participate and 363 persons did not respond. Given the original sample size of 997 persons and the 'deadwood' of 104 persons, the response rate was 55\%. Two-third of the respondent group were women. The average age of the respondents was 69 years and $40-45 \%$ lived on their own, being single, divorced/separated or widowed. Almost $75 \%$ of the respondents described their health 
Sixma, H.J., Calnan, S., Calnan, M., Groenewegen, P.P.

User involvent in measuring service quality of local authority occupational therapy

services: a new approach.

International Journal of Consumer Studies: 25, 2001, nr. 2, p. 150-159

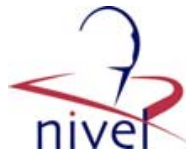

status as 'poor' or 'fair'. With respect to the age and gender distribution of the respondents, it was established that these distributions closely matched the distribution of the population of OT Bureau service users (that is, twothirds over 65 years and two-thirds females).

As part of the QUOTE-OT services instrument, importance and performance were measured by fourpoint response categories. Importance ratings assigned to four-point categories ( 1 = 'not important', 2 = 'fairly important', 3 = 'important' and 4 = 'extremely important') for each of the 40 quality aspects included in the QUOTE-OT instrument were converted into scores between 0 and $10 .^{36}$ Performance scores for all 40 quality aspects, originally rated on four-point Likert scales ( 1 = 'no', 2 = 'not really', 3 = 'on the whole, yes' and 4 = 'yes') were calculated by combining percentages 'yes' and 'on the whole, yes'. Importance (I) and performance (P) scores were combined into quality impact indices (QI), applying the formula QI = I x (1-P). The 40 quality aspects were grouped together in eight quality of care (sub)dimensions. Except for the 'costs' dimension (Cronbach's alpha: 0.53; three aspects), the sub-dimensions form reliable scales (Cronbach's alpha >0.75).

The data set was analysed using item and inter-item analyses, explorative factor analysis (Principal Component Analysis with varimax rotation) and reliability analysis. Differences in means and percentages between respondent groups were analysed using a $P=0.05$ level of significance.

\section{RESULTS OF THE FEASIBILITY STUDY}

The rationale behind the QUOTE-framework, that not all quality aspects are equally valued by users, was confirmed in the feasibility study. Some quality aspects were highly valued; others were rated as 'fairly important' or 'unimportant'.

Table 1 offers different types of information relevant to user groups and quality assurance policies. Firstly, the relative importance of the 40 quality indicators is shown in the first column (I-scores). On a 0 ('not important') to 10 ('extremely important') scale, importance scores vary between 8.5 (aspect nr. 38) to 5.9 (aspect nr. 2 and aspect nr. 30). Secondly, the perceived performance of the OT-service bureau and OT-workers can be deduced from the P-column in Table 1. The performance score 44 for aspect nr. 1 ('complaint procedures are explained to the OT-user') indicates that $44 \%$ of the respondents got such information. High performance ratings refer to better quality of care and less possibilities for quality improvement. Performance scores vary between 34 (aspect nr. 2) and 95 (aspect nr. 40).

\section{[ TABLE 1 ]}

Thirdly, the relative impact of priorities and performances on the overall quality of care concept can be deduced from the QI-columns of Table 2. These quality impact scores can be seen as a weighted score of importance and performance ratings. The importance of item 7 ('OT-service and OT-workers should carry out an annual follow-up check to see if adaptations and/or equipment are still appropriate') is valued at 7.6, and 37\% of the respondents reported that their OT-Bureau did not supply this service. The quality impact $(\mathrm{QI}=2.8)$ is rather high, as a result of the product of a relatively low performance score $(P=37)$ and a high importance score $(I=7.6)$. QI-scores are presented in Table 2 in a descending order. According to these quality impact indices, OT-user groups that want to be involved in setting priorities for quality improvement activities should focus on aspects with relatively high importance scores (above 7.0) and a quality impact score well above 1.0. QIscores above 1.0 indicate sufficient room for improvement on this particular aspect. However, other workable solutions are also possible. If, for example, one wishes to emphasize differences in importance scores between the quality aspects included in the instrument, one could decide on using squared values of the I(mportance) component instead of the original values between 0 and 10 . Also, inclusion criteria for items to be included in a quality improvement programme can vary. For example, one could concentrate on the top-10 or top-15 of the most important quality aspects, instead of looking at aspects with an importance score that exceeds 7.0.

\section{[ TABLE 2 ]}


Sixma, H.J., Calnan, S., Calnan, M., Groenewegen, P.P.

User involvent in measuring service quality of local authority occupational therapy

services: a new approach.

International Journal of Consumer Studies: 25, 2001, nr. 2, p. 150-159

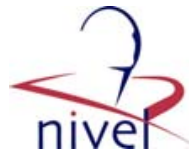

Importance scores for the 40 quality aspects are relatively stable for subcategories within the respondent group. When broken down by gender and perceived health, no systematic differences were found between these subcategories. When broken down by educational level ('less than 10 years' vs. ' 10 years of more'), age ('less than 65 years of age' vs. ' 65 years or older') and disability level ('moderately limited' vs. 'severely limited'), importance scores increase with the level of education and the disability level, while younger people rank the importance of the 40 quality aspects systematically higher than older people. With regard to the performance scores, there is a tendency that men are somewhat more critical than women, that older people give somewhat lower performance scores than younger people, and that severely disabled people give higher performance rankings than people who experience moderate disabilities. As higher importance scores were associated with higher performance ratings ( $\mathrm{r}_{\text {mean }}=0.12$ ), differences in QI-scores for subcategories broken down by respondent characteristics were small.

Although less relevant for quality improvement purposes, QUOTE survey results also allow comparison of services on subdimensions of quality of care. Aggregated importance scores (ranging from 0 'not important' to 10 'extremely important') and performance scores (ranging from 0 'extremely bad performance' to 10 'extremely good performance') for eight quality of care subdimensions are shown in Table 2.

Table 2 illustrates that, in general, OT-user groups should concentrate on quality aspects that relate to the courtesy of the OT-Bureau and its OT-workers and to aspects that refer to the professional competence of the service. These subdimensions receive relatively high importance scores. Relatively low importance scores were found for aspects that are related to the costs of OT-services and the 'perceived autonomy' dimension. Looking at the aggregated performance scores for this particular OT-Bureau, the highest ratings refer to the courtesy dimension and the dimension that can be labelled as 'professional competence'. The 9.4 score for the courtesy sub-dimension indicates that, on average, $94 \%$ of the respondents report 'good performance' on the quality aspects that relate to this subdimension. Relatively low performance ratings are assigned to the subdimensions 'costs' and 'assessment procedures'.

Finally, the conceptual framework behind instruments such as the QUOTE-OT Services instrument and the inclusion of generic aspects means it is possible to make cross-service comparisons. In Fig. 1, overall performance ratings for the OT-Bureau are compared with the services offered by general practitioners (GPs) and hospital consultants. This comparison is based upon performance ratings on 19 aspects that the QUOTE-OT Services instrument and the QUOTE-Disabled instrument had in common.

\section{[ FIGURE 1}

Aspects were grouped together in 'process quality' (courtesy, information, professional competence, perceived autonomy), 'structure quality' (continuity of care, accessibility and availability, costs, assessment procedures) and 'overall quality' (all eight subdimensions). Figure 1 illustrates that weighted performance scores for the Kent Social Services OT-Bureau were somewhat below the performance scores of general practitioners and somewhat above the performance scores of hospital services and hospital consultants.

\section{CONCLUSIONS AND DISCUSSION}

This article aimed to (i) describe the development of a new measuring instrument for quality of care from the perspective of the users of local authority Occupational Therapy (OT) services, and (ii) evaluate the potential of the new instrument as a standardized approach for involving users in the evaluation of home health care services.

One of the problems with satisfaction surveys is that users are seldom involved in the process of developing patient satisfaction scales or other instruments measuring quality of care. As a consequence, one can question the validity of such instruments for measuring quality of care from the users' perspective. The development process of the QUOTE-family of instruments, including the QUOTE-OT instrument, involves users in this process from the very beginning. In this specific study, users of OT services were involved initially by identifying and prioritizing aspects of quality of care 
Sixma, H.J., Calnan, S., Calnan, M., Groenewegen, P.P.

User involvent in measuring service quality of local authority occupational therapy

services: a new approach.

International Journal of Consumer Studies: 25, 2001, nr. 2, p. 150-159

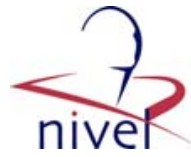

during the focus groups and concept mapping meetings, secondly by commenting on earlier drafts of the instrument, and thirdly by completing the questionnaires as part of the feasibility study for the QUOTE-OT Services instrument.

Working with focus groups has the disadvantage of 'small group' bias. To avoid this pitfall, results from two focus groups with users were compared with findings from other quality of care studies ${ }^{20-24}$ and with verbatim written comments on an 'open question' in the quantitative part of the study, that asked for additional quality aspects. Based on the content analysis of these written comments, only a limited number of additional quality aspects were mentioned. ${ }^{37}$ Other possible disadvantages of FGDs were minimized by using a combination of this qualitative research method with a large(r) scale survey study. From the researchers' perspective, focus groups proved to be an efficient way of identifying salient concerns of consumers and resulted in a better understanding of phenomena that were of key importance to the users of the services of an OT-Bureau. For the clients of the OT-Bureau that participated in the FGDs, the meetings offered a platform for mentioning and discussing their views on 'good service quality' at the beginning of a research and development (R \& D) study.

The second aim of our study was to look at the potential of the QUOTE-OT instrument to evaluate and improve the services of a local authority OT Bureau from the users point of view. Survey results from the feasibility study yielded specific information about the quality of services provided by the OT Bureau. User groups can benefit from the kind of information that is derived from instruments like the QUOTE-OT Services, especially in areas in which there seems to be room for quality improvement, such as the accessibility of the OT service, the information that is given to users and assessment and follow-up procedures. Quality impact indices, such as the ones presented in this study, provide such groups with useful information about specific quality aspects that are relevant and leave sufficient room for quality improvement. Also, combining importance and performance scores on the level of relevant subsamples means that quality improvement programmes can be tailored to the wishes and expectations of these specific groups. For example, user groups could aim at improving specific services for people who are above 75 years of age, people who are severely disabled or people with specific chronic diseases. Here, the limiting factors are the size of the sample and subsamples and whether or not these (sub)samples are representative of the population they were sampled from. Based on information that is provided by quality impact scores, user groups can set their own priorities in discussions with local authorities and providers of health and social care services at the start of quality improvement programmes. Survey results, as presented in this article, can therefore facilitate user groups in setting the agenda for quality improvement programmes and contribute to the (further) empowerment of such groups. However, whether or not such user groups are actually taken seriously as stakeholders and are able to reach real power sharing depends on other factors than just sharing information.

Constructing a new instrument like the QUOTE-OT Services questionnaire is like placing money on two different horses. All 43 aspects included in the final version of the instrument (three aspects derived from the 'open questions' were added to the 40 aspects included in the preliminary version of the QUOTE-OT instrument) contribute to the face validity of the instrument and provide user groups with useful information for quality improvement programmes. However, from the point of response rates and to minimize distress (especially) to elderly people, an instrument with 43 quality aspects might be somewhat lengthy. Therefore, two shorter versions with 23 or 12 key items were developed which are less resource intensive for providers, less arduous for users to complete and still provide an adequate 'quick scan' of the service quality of local OT services.

The QUOTE family of instruments is based on a conceptual framework that builds on the sequence: expectations - performance - importance - impact. Expectations (or 'needs') of users are derived from and further specified in FGDs and should reflect the multi dimensionality of the care-giving process. With respect to the 'performance' component we agree with Cleary and Edgman-Levitan ${ }^{19}$ that questions asking for 'reports' tend to reflect better the quality of care and are more interpretable and actionable for quality improvement purposes than ratings of satisfaction. As some quality aspects are more valued than others, the importance component of the model can function as a weight factor in evaluating the performance scores as part of quality improvement plans.

Whether used at the start of a process of continuous quality improvement or to provide a 'quick scan', it is important to realize that user involvement should not be limited to the development phase 
Sixma, H.J., Calnan, S., Calnan, M., Groenewegen, P.P.

User involvent in measuring service quality of local authority occupational therapy services: a new approach.

International Journal of Consumer Studies: 25, 2001, nr. 2, p. 150-159

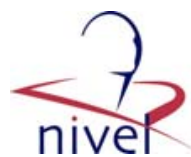

of a measuring instrument. Users should also be involved in (1) policy developments and the implementation of quality improvement programmes that are based on survey results, (2) a regular review of the instrument, so that it remains sensitive to users' needs and experiences, and (3) the selection of 'local' topics that could be added to the basic set of quality aspects in order to tailor the instrument to specific local needs. When applied in this way, instruments like the QUOTE-OT Services could contribute to the further empowerment of user groups and patient organizations.

\section{ACKNOWLEDGEMENTS}

The research project 'Quality of Care from the Patients' Perspective: The Development and Assessment of a series of new measuring instrument', on which this manuscript is based, was supported by research funds from the Netherlands Organization for Scientific Research (NWO 94020-054, NWO 940-20-097 and NWO 940-20-806). Thanks to Jackie Newton and Marion Prior for coordinating the survey and to all the anonymous users who participated in the study.

\section{TABLES AND FIGURES}

Table 1 Importance scores, performance scores and quality impact indices of 40 aspects included in a preliminary version of the QUOTE-OT instrument for users of the OT-Bureau, Kent Country Council

\begin{tabular}{|c|c|c|c|c|}
\hline & Aspect & $\begin{array}{l}\text { Importance (I) } \\
(0-10 \text { scale })\end{array}$ & $\begin{array}{c}\text { Performance }(P) \\
\text { (\% 'yes') }\end{array}$ & $\begin{array}{l}\text { Quality impact (QI) } \\
\qquad \mathrm{I} \times(100-\mathrm{P}) / 100\end{array}$ \\
\hline 1 & Explanation complaint procedure & 7.1 & 44 & 4.0 \\
\hline 2 & Showroom for equipment & 5.9 & 34 & 3.9 \\
\hline 3 & No charges for equipment & 6.6 & 45 & 3.6 \\
\hline 4 & Annual report on situation/conditions & 6.0 & 42 & 3.5 \\
\hline 5 & Reimbursement of extra expenses & 6.7 & 49 & 3.4 \\
\hline 6 & Easy to reach by public transport & 7.0 & 51 & 3.4 \\
\hline 7 & Annual follow-up check on adaptations & 7.6 & 63 & 2.8 \\
\hline 8 & Explanation financial consequences & 6.8 & 61 & 2.7 \\
\hline 9 & Provision specialized back-up services & 7.0 & 63 & 2.6 \\
\hline 10 & Users decide on spending care budget & 6.1 & 57 & 2.6 \\
\hline 11 & Check on adaptations after 2 weeks & 7.7 & 68 & 2.5 \\
\hline 12 & Information about results with other services & 7.1 & 65 & 2.5 \\
\hline 13 & Minimize bureaucratic procedures & 7.6 & 68 & 2.4 \\
\hline 14 & Assessment 4 weeks after request & 7.4 & 69 & 2.3 \\
\hline 15 & Take account of family needs & 7.5 & 72 & 2.1 \\
\hline 16 & Information on range of services & 7.7 & 74 & 2.0 \\
\hline 17 & Accessibility of OT-office & 8.0 & 78 & 1.8 \\
\hline 18 & Good communications with other services & 7.4 & 75 & 1.8 \\
\hline 19 & One coordinating key person & 7.2 & 76 & 1.8 \\
\hline 20 & Replacement when OT-worker is absent & 6.7 & 73 & 1.8 \\
\hline 21 & Services that cover my needs & 8.2 & 79 & 1.7 \\
\hline 22 & Explanation reasons adadptations & 7.4 & 77 & 1.7 \\
\hline 23 & Information about length of waiting times & 7.0 & 76 & 1.7 \\
\hline 24 & Discuss careplan with me & 7.8 & 80 & 1.6 \\
\hline 25 & Services allowing more independence & 7.8 & 80 & 1.6 \\
\hline 26 & Availibility of appropriate equipment & 8.1 & 82 & 1.5 \\
\hline 27 & Adaptations/equipment delivered on time & 7.5 & 80 & 1.5 \\
\hline 28 & Cost/benefits assessment & 6.3 & 78 & 1.4 \\
\hline 29 & Easy to reach by telephone & 7.6 & 83 & 1.3 \\
\hline 30 & Possibility to see personal files & 5.9 & 79 & 1.2 \\
\hline 31 & Possibility to choose different OT-worker & 6.5 & 86 & 0.9 \\
\hline 32 & Good understandig of problems & 8.2 & 90 & 0.8 \\
\hline 33 & Listen to my views & 8.0 & 90 & 0.8 \\
\hline 34 & Efficient work & 7.9 & 90 & 0.8 \\
\hline 35 & Input in decisions for users & 7.3 & 91 & 0.8 \\
\hline 36 & Users are taken seriously & 8.1 & 93 & 0.6 \\
\hline 37 & Enough time & 7.5 & 92 & 0.6 \\
\hline 38 & Don't make me feel as a burden to society & 8.5 & 94 & 0.5 \\
\hline 39 & Keep appointments punctually & 6.7 & 92 & 0.5 \\
\hline 40 & Respect privacy of client & 8.4 & 95 & 0.4 \\
\hline
\end{tabular}


Sixma, H.J., Calnan, S., Calnan, M., Groenewegen, P.P.

User involvent in measuring service quality of local authority occupational therapy services: a new approach.

International Journal of Consumer Studies: 25, 2001, nr. 2, p. 150-159

Table 2 Importance and performance ratings for eight quality of care subdimensions, on a scale ranging from 0 ('extremely low') to 10 ('extremely high')

\begin{tabular}{lcc}
\hline QoC subdimensions & $\begin{array}{c}\text { Importance } \\
(\mathrm{I})\end{array}$ & $\begin{array}{c}\text { Performance } \\
(\mathrm{P})\end{array}$ \\
\hline 'Process quality' & & \\
$\quad$ courtesy & 8.2 & 9.4 \\
informativeness & 7.2 & 6.7 \\
perceived autonomy & 6.8 & 7.8 \\
professional competence & 8.0 & 8.3 \\
'Structure quality' & & \\
continuity of care & 7.1 & 7.5 \\
accessibility/availibility of services & 7.3 & 6.7 \\
costs & 6.5 & 5.8 \\
assessment procedures & 7.2 & 6.2 \\
\hline
\end{tabular}

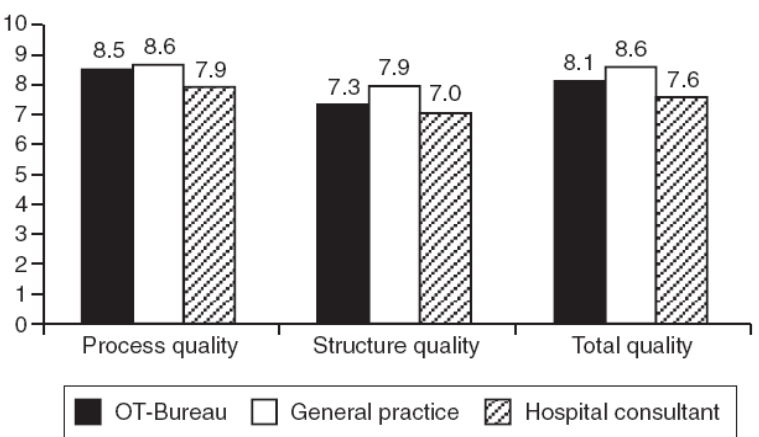

Figure 1 Comparison between the OT-Bureau and the services of general practice and hospital consultants, on 'process' quality, 'structure' quality and 'total' quality.

\section{REFERENCES}

1. Marquis, M.S., Ross Davies,A. \& Ware, J.E. (1983) Patient satisfaction and change in medical care provider: a longitudinal study. Medical Care, 21, 821-829.

2. Wartman, S.A., Morlock, L.L., Malitz, F.E. \& Palm, E.A. (1983) Patient understanding and satisfaction as predictors of compliance. Medical Care, 21, 886-891.

3. Thomas, J.W. (1984) Relating satisfaction with access to utilization of services. Medical Care, $22,553-568$.

4. Donabedian, A. (1988) Quality assessment and assurance: unity of purpose, diversity of means. Inquiry, 25, 173-192.

5. Donabedian, A. (1988) The quality of care: how can it be assessed? Journal of the American Medical Association, 260, 1743-1748.

6. Donabedian, A. (1992) Quality assurance in health care: consumers' role. Quality in Health Care, 1, 247-251.

7. Aharony, L. \& Strasser, S. (1993) Patient satisfaction: what we know about and what we still need to explore. Medical Care Review, 50, 49-70.

8. Rubin, H.R.,Ware, J.E. \& Hays, R.D. (1990) The PJHQ questionnaire; exploratory factor analysis and empirical scale construction. Medical Care, (9), S22-S29.

9. Williams, B. (1994) Patient satisfaction: a valid concept? Social Science and Medicine, 38 , 509-516.

10. Ross, C.A., Steward, C.A. \& Sinacone, J.M. (1995) A comparative study of seven measures of patient satisfaction. Medical Care, 33, 392-406.

11. Strasser, S., Aharony, L. \& Greenberger, D. (1993) The patient satisfaction process: moving toward a comprehensive model. Medical Care Review, 50, 219-248.

12. Øvretveit, J. (1992) Health service quality. an introduction to quality methods for health services. Blackwell Scientific, London.

13. Campen, C., Sixma, H., Friele, R.D., Kerssens, J.J. \& Peters, L. (1995) Quality of care and patient satisfaction: a review of measuring instruments. Medical Care Research and Review, 52, 109-133. 
Sixma, H.J., Calnan, S., Calnan, M., Groenewegen, P.P.

User involvent in measuring service quality of local authority occupational therapy

services: a new approach.

International Journal of Consumer Studies: 25, 2001, nr. 2, p. 150-159

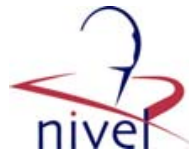

14. Nederlands Normalisatie Instituut (1992) Kwaliteitszorg en elementen van een kwaliteitssysteem, deel 2: richtlijnen voor diensten. Nederlandse Norm. NEN-ISO 9004.2. Nederlands Normalisatie Instituut, Delft.

15. Lebow, J.L. (1993) Research assessing consumer satisfaction with mental health treatment: a review of findings. Evaluation and Program Planning, 6, 211-236.

16. Parasuraman, A., Zeithaml,V.A. \& Berry, L.L. (1985) A. conceptual model of service quality and its implications for future research. Journal of Marketing, 49, 41-50.

17. Parasuraman, A., Zeithaml,V.A. \& Berry, L.L. (1988) SERVQUAL. a multiple-item scale for measuring consumer perceptions of service quality. Journal of Retailing, 64, 12-40.

18. Zastowny, T.R., Stratmann,W.C., Adams, E.H. \& Fox, M.L. (1995) Patient satisfaction and experience with health services and quality of care. Quality Management in Health Care, 3, 50-61.

19. Cleary, D.C. \& Edgman-Levitan, S. (1997) Health care quality; incorporating consumer perspectives. Journal of the American Medical Association, 278 (19), 1608-1612.

20. Ware, J.E., Snyder, M.K., Wright,W.R. \& Davies, A.R. (1983) Defining and measuring patient satisfaction with medical care. Evaluation and Program Planning, 6, 247-236.

21. Hall, J.A. \& Dornan, M.C. (1990) Patient sociodemographic characteristics as predictors of satisfaction with medical care: a meta-analysis. Social Science and Medicine, 30, 811-818.

22. Hall, J.A. \& Dornan, M.C. (1988) What patients like about their medical care and how often they are asked: a meta-analysis of the satisfaction literature. Social Science and Medicine, 27, 935-939.

23. Wensing, M., Grol, R. \& Smits,A. (1994) Quality judgements by patients on general practice care: a literature analysis. Social Science and Medicine, 38, 45-53.

24. Stamps, P.L. \& Berger Finkelstein, J. (1981) Statistical analysis of an attitude scale to measure patient satisfaction with medical care. Medical Care, 19, 1108-1135.

25. Linder-Pelz, S. \& Struening, E.L. (1985) The multidimensionality of patient satisfaction with a clinic visit. Journal of Community Health, 10, 42-54.

26. Consumers in NHS Research Support Unit (2000) Involving consumers in research and development in the NHS: brieving notes for researchers. The Help for Health Trust, Winchester.

27. Campen, C., Sixma, H.J., Kerssens, J.J. \& Peters, L. (1997) Assessing non-institutionalized asthma and COPD patients' priorities and perceptions of quality of health care; the development of the QUOTE-CNSLD instrument. Journal of Asthma, 11, 531-538.

28. Campen, C., Sixma, H.J., Kerssens, J.J. \& Peters, L. (1998) Assessing patients' priorities and perceptions of quality of health care; the development of the QUOTErheumatic- patients instrument. British Journal of Rheumatology, 37, 362-368.

29. Schouten, G., Sixma, H. \& Friele, F. (2000) De QUOTEdiabetes vragenlijst. Netherlands institute for health services research, Utrecht (the Netherlands).

30. Sixma, H.J., van Campen, C., Kerssens, J.J. \& Peters, L. (2000) Quality of care from the persective of elderly people: the QUOTE-elderly instrument. Age and Ageing, 29, 173-178.

31. Sixma, H.J., Calnan, M.W. \& Groenewegen, P.P. (submitted) Quality of care from the perspective of disabled people; cross-cultural adaptation of a new measuring instrument.

32. Sixma, H.J., Kerssens, J.J., van Campen, C. \& Peters, L. (1998) Quality of care from the patients' perspective: from theoretical concept to a new measuring instrument. Health Expectations, 2, 82-95.

33. Morgan, D. (1988) Focus groups as qualitative research. Sage, London.

34. Kitzinger, J. (1994) The methodology of focus groups: the importance of interaction between research participants. Sociology of Health and Illness, 16, 103-121.

35. Trochim,W.M.K. (1993) The Concept System. Concept Systems, Ithaka (NY).

36. Tabachnick, B.G. \& Fidell, L.S. (1996) Using Multivariate Statistics. HarperCollins College Publishers, New York (NY).

37. Sixma, H.J., Calnan, M.W., Groenewegen, P.P. \& Calnan, S. (1999) Quality of care from the perspective of occupational therapy users. Final report. Netherlands institute for health services research, Utrecht (the Netherlands). 